\title{
A home based health check combined with influenza vaccination improved uptake of influenza vaccination in people $\geq 75$ years of age
}

\author{
Arthur AJ, Matthews RJ,Jagger C, et al. Improving uptake of influenza vaccination among older people: a randomised \\ controlled trial. Br J Gen Pract 2002;52:717-22. \\ QUESTION: In people $\geq 75$ years of age, what is the effectiveness of 2 services (a \\ home based health check combined with influenza vaccination and a personal letter of \\ invitation to attend an influenza vaccination clinic) for maximising uptake of influenza \\ vaccination?
}

\section{Design}

Randomised (unclear allocation concealment), blinded \{data collectors $\}^{*}$, controlled trial with follow up of approximately 14 weeks.

\section{Setting}

A primary care practice in Melton Mowbray, Leicestershire, UK.

\section{Patients}

Source of funding: Melton, Rutland, and Harborough Primary Care Group and Leicestershire Health.

For correspondence: Dr A J Arthur, School of Nursing, Faculty of Medicine and Health Sciences, University of Nottingham, Nottingham, UK tony.arthur@ nottingham.ac.uk women) who were registered at a primary care practice. Adults living in residential care, nursing homes, or sheltered accommodation were excluded. Follow up was $100 \%$.

\section{Intervention}

680 patients were allocated to an offer for a health check (including assessment of physical and mental health) given by a practice nurse in the patient's home combined with an offer for influenza vaccination (health check group). 1372 patients were allocated to receive a personal

Home based health check plus influenza vaccination (health check) v personal letter of invitation to attend a vaccination clinic (personal letter) in people $\geq 75$ years of aget

\begin{tabular}{lllll}
$\begin{array}{c}\text { Outcome at } \\
\text { approximately } 3 \\
\text { months }\end{array}$ & Health check & $\begin{array}{l}\text { Personal } \\
\text { letter }\end{array}$ & RBI (95\% Cl) & NNT (CI) \\
\hline $\begin{array}{l}\text { Receipt of influenza } \\
\text { vaccination }\end{array}$ & $74 \%$ & $68 \%$ & $9 \%(3$ to 16$)$ & 16 (10 to 46$)$ \\
\hline
\end{tabular}

letter of invitation to attend an influenza vaccination clinic (personal letter group). The letter stressed the importance of vaccination and reassured patients that there were few vaccination associated adverse effects.

\section{Main outcome measures}

Proportion of patients receiving the influenza vaccination.

\section{Main results}

Analysis was by intention to treat. Among the 680 patients in the health check group, $468(69 \%)$ actually received the health check. Among the 1372 patients in the personal letter group, $66(4.8 \%)$ received the influenza vaccination at home because of medical reasons. Participants in the health check group were more likely to receive the influenza vaccination than those in the personal letter group (table). Among those who had not received influenza immunisation in the previous year, patients in the health check group achieved a higher inoculation rate than those in the personal letter group.

\section{Conclusion}

In patients $\geq 75$ years of age, a home based health check combined with influenza vaccination improved uptake of influenza vaccination more than an invitation to attend a vaccination clinic.

*Information provided by author.

\section{COMMENTARY}

Influenza is a common respiratory illness caused by influenza viruses. It occurs mainly in winter, has a sudden onset, and is characterised by fever, chills, myalgia, headache, cough, and sore throat. For most people, influenza is self limiting, although unpleasant. However, for those in high risk groups (eg, people who are elderly, immunosuppressed, or have chronic conditions, such as respiratory, cardiac, or renal disease, or diabetes), it can be life threatening. In the UK, annual mortality caused by influenza ranges from 3000-4000 deaths. ${ }^{1}$ However, this increases during epidemics. During the epidemic of $1989-90,29000$ "flu related deaths" occurred in the UK.

The influenza vaccine reduces infection, illness, hospital admissions, and deaths in older persons, ${ }^{2}$ who if vaccinated every year, have greater protection than those vaccinated for the first time. ${ }^{3}$ Increasing uptake of the influenza vaccine can potentially reduce the morbidity and mortality of influenza in high risk groups. In the UK, vaccination is usually delivered in general practices, typically by nurses. The UK Department of Health has set a target that $70 \%$ of people $>65$ years of age should be vaccinated.

The studies by Arthur $e t$ al and Hull $e t$ al describe 2 methods that aim to increase uptake of the influenza vaccine: offering it as part of a health check (Arthur et al) or a telephone invitation from a practice receptionist (Hull $e t a l$ ). Both interventions showed increased uptake of the vaccine.

Neither study provided details on where clinics were held or if flexibility of timing was given to better suit patients. This information is important to the interpretation of the study by Hull et al, which addresses a multi-ethnic, transient, and therefore, hard to reach population. It would also be useful to know more about the health information that was provided by receptionists in the study by Hull $e t$ al and by the nurses in the study by Arthur $e t$ al. For example, were "scripts" used? How were the dangers of flu described?

The model used in the study by Arthur $e$ al, where nurses included the flu vaccine within the health check, may not (as the authors suggest) be practical because it is costly in terms of nursing time. Practice nurses have a heavy workload during the autumn months, vaccinating large numbers of patients (eg, 2 nurses vaccinate about 60 patients/h in the author's practice), and the population $>65$ years is increasing. 


\section{Telephone appointing by receptionists improved uptake of influenza immunisation in low risk people aged 65-74 years}

Hull S, Hagdrup N, Hart B, et al. Boosting uptake of influenza immunisation: a randomised controlled trial of telephone appointing in general practice. Br J Gen Pract 2002;52:712-6.

\section{QUESTION: In elderly patients aged $65-74$ years who have not previously been recalled for influenza immunisation, is telephone appointing by receptionists effective for improving uptake of influenza immunisation?}

\section{Design}

Randomised \{allocation concealed\}*, blinded \{healthcare providers, data collectors, data analysts $\}^{*}$, controlled trial with approximately 3 months of follow up.

\section{Setting}

3 general practices in London and Essex, UK.

\section{Patients}

1318 patients who were 65-74 years of age and registered at 1 of 3 general practices that serve a multiethnic, inner city population. Patients with chronic disease who had been previously recalled for influenza immunisation were excluded. Follow up was $100 \%$.

\section{Intervention}

1206 households (1318 patients, mean age 69 y, 55\% women), which were grouped within each practice, were allocated to telephone appointing (intervention group, 605 households, 660 patients) or to the control group (601 households, 658 patients). Each household in the intervention group received $\leq 2$ telephone contacts (made at different times during the day) by a receptionist who offered to make an appointment for influenza vaccination at a nurse run clinic. The study coincided with a letter and leaflet mailout to every general practice registered patient aged $\geq 65$ years, which promoted influenza immunisation uptake, and a national television campaign promoting influenza immunisation.

\author{
Main outcome measure \\ Uptake of influenza immunisation.
}

\begin{abstract}
Main results
Analysis was by intention to treat. Of the 605 households in the intervention group, 360 (59.5\%) were contacted by telephone, $30(5 \%)$ already had an appointment for influenza vaccination, $102(17 \%)$ could not be contacted by telephone, and 113 (19\%) had no telephone. A higher rate of uptake of influenza immunisation was seen among patients in the intervention group than in the control group (table).
\end{abstract}

\section{Conclusion}

In elderly patients aged 65-74 years who had not previously been recalled for influenza immunisation, telephone appointing by receptionists improved uptake of influenza immunisation.

*Information provided by author.

Source of funding: East London and Essex Network of Researchers.

For correspondence: Dr S A Hull, Department of General Practice and Primary Care, Medical Sciences Building, Queen Mary College, London, UK. s.a.hull@qmw.ac.uk

Telephone appointing $v$ control for uptake of influenza immunisation in elderly patients $†$

\begin{tabular}{lllll}
$\begin{array}{c}\text { Outcome at } \\
\text { approximately } 3 \\
\text { months }\end{array}$ & $\begin{array}{l}\text { Telephone } \\
\text { appointing }\end{array}$ & Control & RBI (95\% Cl) & NNT (Cl) \\
$\begin{array}{l}\text { Uptake of influenza } \\
\text { immunisation }\end{array}$ & $50 \%$ & $44 \%$ & $14 \%(1$ to 28$)$ & 17 (9 to 186) \\
\hline
\end{tabular}

\section{COMMENTARY — continued from previous page}

An economic analysis would help readers place the effects of these interventions into context. Practices in the UK receive an item of service payment for each vaccination given to persons $>65$ years. However, this cost will be offset by reduced visits to general practitioners, home visits, drugs, and hospital admissions, plus the advantage to patients of illness prevention.

A recent systematic review identified that organisational changes, such as separate clinics, deployment of non-medical staff (eg, nurses), patient financial incentives, and patient reminders are the most effective ways of improving uptake of adult immunisation and screening. ${ }^{4}$ Clearly, the interventions used in the studies by Arthur $e t a l$ and Hull $e t$ al fit many of these criteria. A package of interventions is most likely to be effective for increasing uptake of vaccination. ${ }^{5}$ It would be interesting to see if the effects of the interventions evaluated here could be further improved by the incorporation of other strategies (eg, patient financial incentives).

These 2 interventions should be seen as part of a larger strategy to vaccinate vulnerable patients. Clinics need to be held at convenient times and be easily accessible. Mobile outreach or weekend clinics may be required. Publicity, ranging from media campaigns to personal letters to patients, needs to be appropriate and widely dispersed in simple language.

Sarah G Giles, RGN, MA Nurse Practitioner, Harewood Medical Practice Catterick Garrison, North Yorkshire, UK

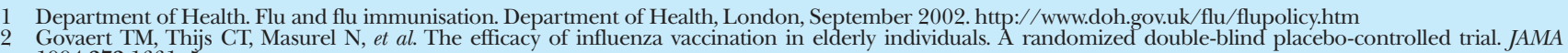
1994;272:1661-5. Ahmed AE, Nicholson KG, Nguyen-Van-Tam JS. Reduction in mortality associated with influenza vaccine during 1989-90 epidemic. Lancet 1995;346:591-5.
Stone EG, Morton SC, Hulscher ME, et al. Interventions that increase use of adult immunization and cancer screening services: a meta-analysis. Ann Intern Med Kassianos G. Boosting influenza immunisation for the over-65s. Br J Gen Pract 2002;52:710-1. 